\title{
EFFECTS OF SOMATOSTATIN ANALOGUES ON MUSCLE SYMPATHETIC NERVE ACTIVITY IN ACROMEGALY
}

C. Carzaniga†, G. Seravalle*, R. Attanasio¥, G. Grassi §, R. Cozzi\#, L. M. Fattiף, M. Montinił, G. Vitale†, G. Sciortino†,

S. Damanti E, F. Cavagnini $\exists$, G. Mancia §, M. Scacchiळ and L. Persani†

†Department of Clinical Sciences and Community Health, University of Milan, Division of Endocrinology and Metabolic Diseases, Ospedale San Luca IRCCS, Istituto Auxologico Italiano, Milan, ${ }^{*}$ Department of Cardiology, Ospedale San Luca IRCCS, Istituto Auxologico Italiano, Milan, ¥Endocrinology, Istituto Galeazzi IRCCS, Milan, $\S$ Department of Clinical Medicine and Prevention, University of Milano-Bicocca, Milan, \#Division of Endocrinology, Ospedale Niguarda Ca' Granda, Milan, IDivision of Endocrinology and Metabolic Diseases, Ospedale San Luca IRCCS, Istituto Auxologico Italiano, Milan, $\ddagger$ Division of Endocrinology, Humanitas Gavazzeni Bergamo, ESubspecialty School of Geriatrics, University of Milan, Milan and $\exists$ Laboratory of Neuroendocrinology, Istituto Auxologico Italiano, Milan, Italy, $\infty$ Department of Clinical Sciences and Community Health, University of Milan, Division of Endocrinology and Metabolic Diseases, Ospedale San Giuseppe IRCCS, Istituto Auxologico Italiano, Oggebbio-Piancavallo (VCO), all in Italy

\section{INTRODUCTION}

Background: we previously demonstrated a markedly decreased adrenergic tone in newly diagnosed acromegalic patients by direct measurement of muscle sympathetic nerve activity (MSNA), in spite of insulin resistance (Seravalle et al., Clin Endocrinol 77:262, 2012). Our data pointed to a phenomenon mediated by hypoleptinaemia rather than a direct action of the GH-IGF-I system.

Aim: It has been shown that centrally administered somatostatin (SS) inhibits peripheral sympathetic outflow in rodents (Rettig et al., Am J Physiol 257:R588, 1989). Based on the above, we elected to study MSNA in acromegalic patients before and during treatment with SS analogues (SSA)

\section{SUBJECTS}

Demographic data of the study population

\begin{tabular}{|c|c|c|c|c|}
\hline & $\begin{array}{c}\text { NEWLY } \\
\text { DIAGNOSED } \\
\text { ACROMEGALICS }\end{array}$ & $\begin{array}{c}\text { UNCONTROLLED } \\
\text { ACROMEGALICS } \\
\text { ON SSA }\end{array}$ & $\begin{array}{c}\text { CONTROLLED } \\
\text { ACROMEGALICS } \\
\text { ON SSA }\end{array}$ & CONTROLS \\
\hline $\mathrm{N}$ & $\mathbf{2 4}$ & 11 & 11 & 17 \\
\hline AGE, yr & $\mathbf{4 5 . 5 \pm 1 3 . 0 2}$ & $56.4 \pm 17.5$ & $52.4 \pm 13.91$ & $49.1 \pm 15.6$ \\
\hline SEX (F/M) & $11 / 13$ & $6 / 5$ & $4 / 7$ & $6 / 5$ \\
\hline
\end{tabular}

Patients on SSA were considered biochemically controlled if their IGF-I levels were within the age-matched reference range and not controlled if IGF-I levels were over the upper limit of the reference range.

\section{RESULTS}

\section{MSNA}
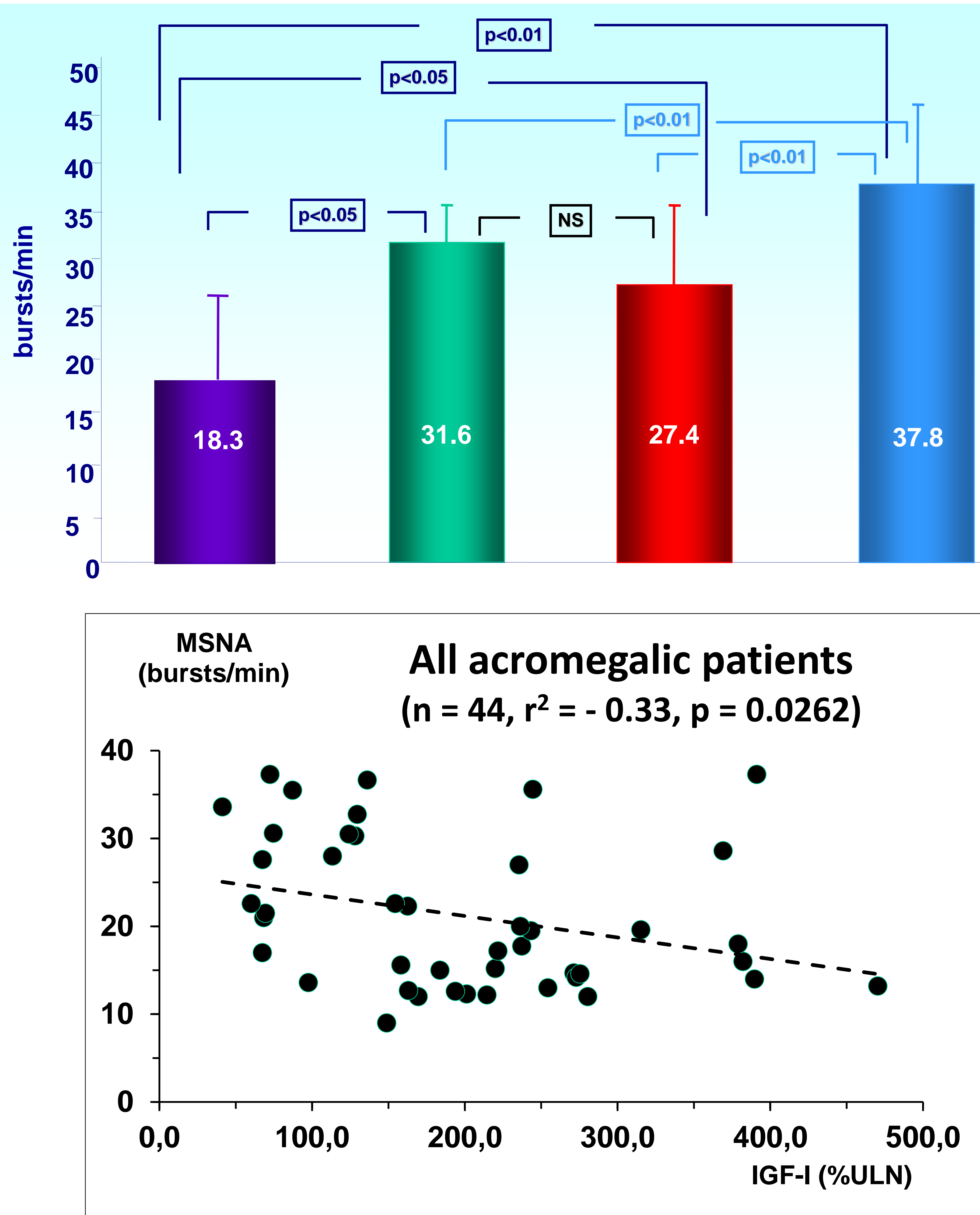

\section{METHODS}

- Evaluation of GH and IGF-I levels

Body composition (bioelectrical impedance analysis)

Direct recording of postganglionic presynaptic sympathetic nerve activity (microneurography, peroneal nerve, MSNA)

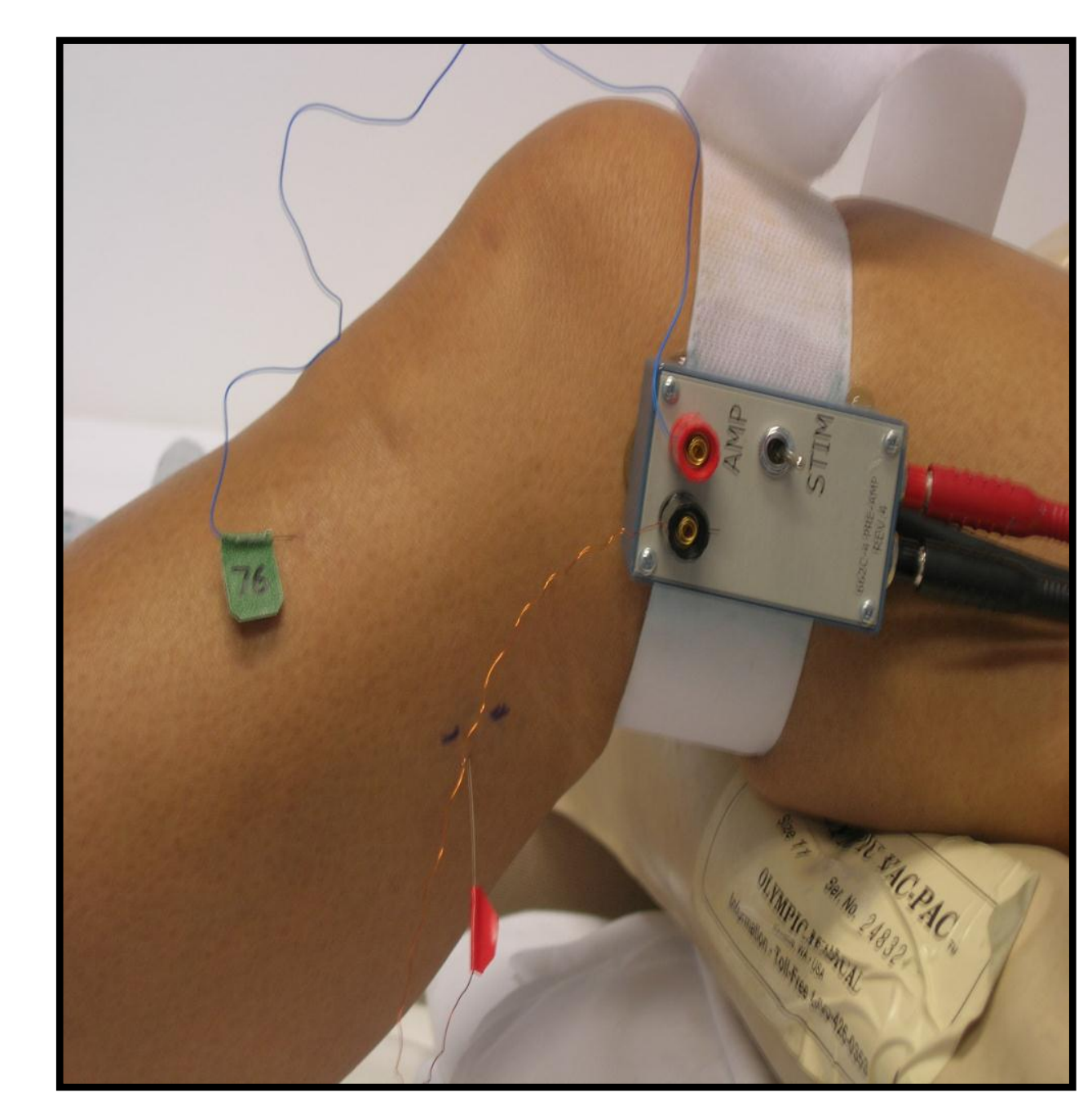

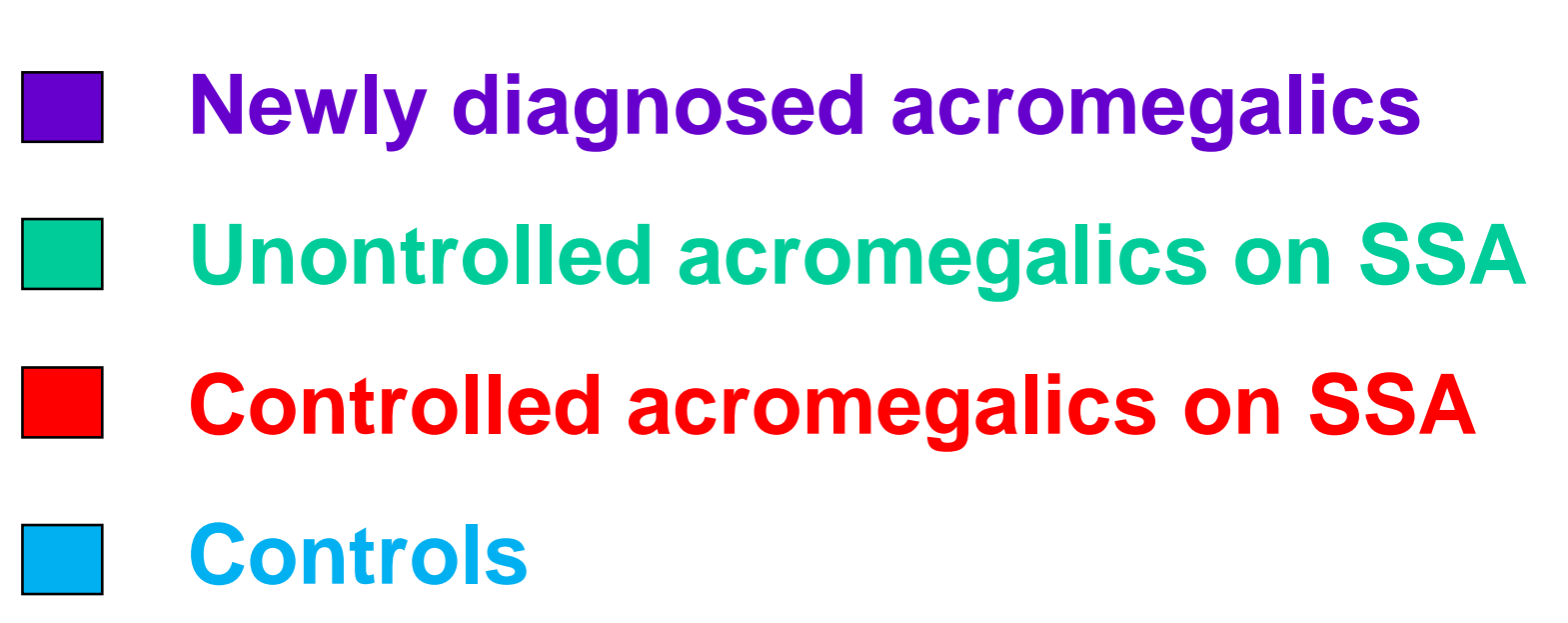

$\square$ Controls

\begin{tabular}{|c|c|c|c|c|}
\hline & $\begin{array}{c}\text { NEWLY } \\
\text { DIAGNOSED } \\
\text { ACROMEGALICS }\end{array}$ & $\begin{array}{c}\text { UNCONTROLLED } \\
\text { ACROMEGALICS } \\
\text { ON SSA }\end{array}$ & $\begin{array}{c}\text { CONTROLLED } \\
\text { ACROMEGALICS } \\
\text { ON SSA }\end{array}$ & CONTROLS \\
\hline $\begin{array}{c}\text { IGF-I (\% of } \\
\text { upper limit) }\end{array}$ & $270.8 \pm 90.19$ & $126.8 \pm 7.69$ & $71.8 \pm 9.02$ & \\
\hline $\begin{array}{c}\text { Basal GH } \\
\text { (mcg/L) }\end{array}$ & $10.9 \pm 10.84$ & $1.8 \pm 1.45$ & $0.9 \pm 0.68$ & \\
\hline $\begin{array}{c}\text { Extracellular } \\
\text { water (L) }\end{array}$ & $19 \pm 4.94$ & $20.1 \pm 5.65$ & $17.2 \pm 2.26$ & $16.9 \pm 4.21$ \\
\hline
\end{tabular}

No significant correlation was found between MSNA on the one hand and GH and extracellular water on the other hand.

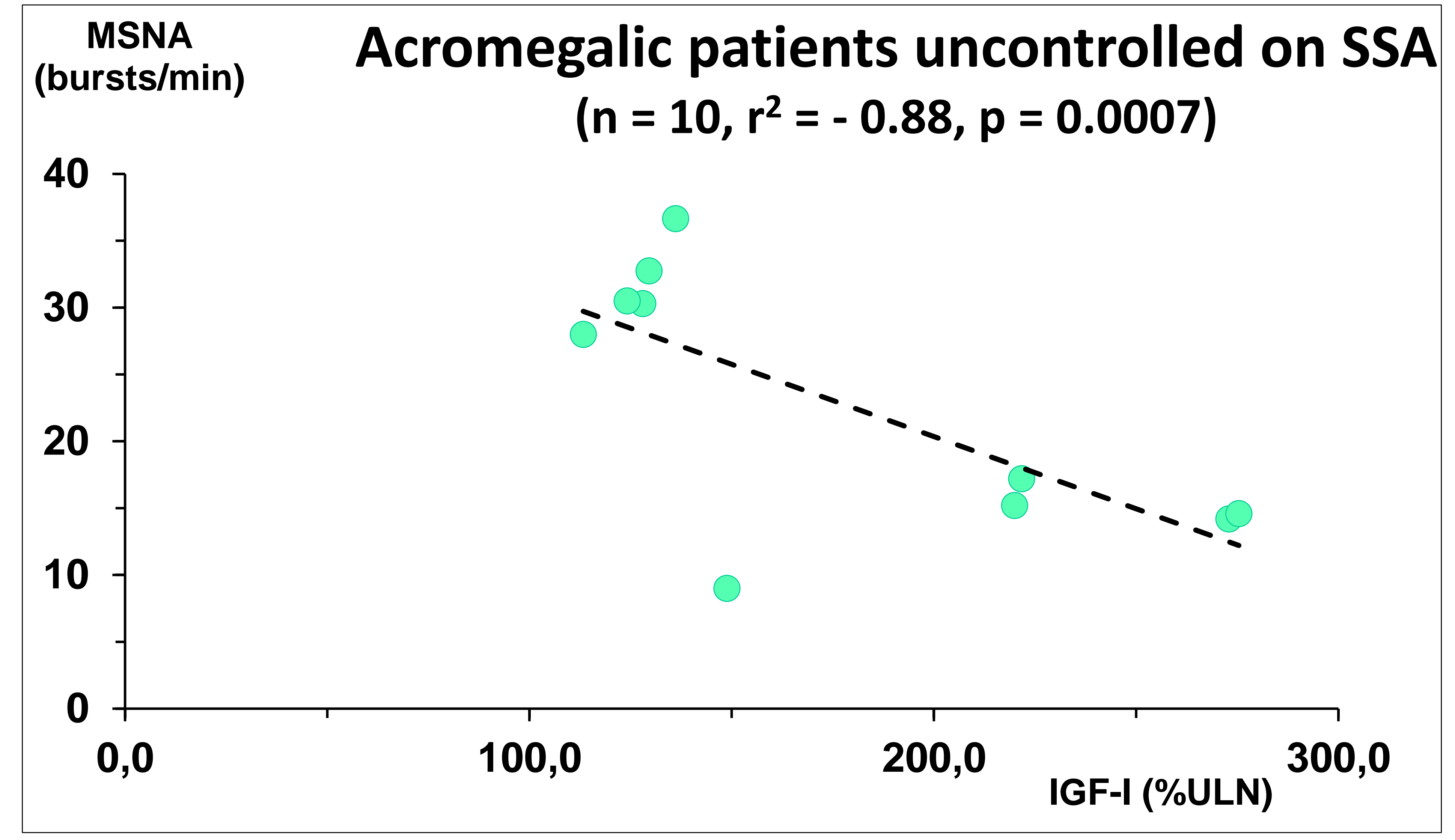

CONCLUSIONS

1) Direct recording of muscle sympathetic nerve activity has confirmed a marked sympathoinhibition in active acromegaly.

2) The treatment of acromegaly by SSA administration appears to be able to reverse, at least in part, the sympathoinhibition of untreated patients.

3) The negative correlation between IGF-I levels and MSNA in acromegalic patients suggests a role of IGF-1 as direct inhibitor of sympathetic outflow.

4) Given the lack of correlation between extracellular water and MSNA, the sympathoinhibition of acromegaly does not seem to be linked to effect of activated baroreceptors.

5) As for the lack of difference in MSNA between controlled and uncontrolled patients, an explanation will likely be provided by studies involving larger series of SSA-treated acromegalic subjects and by the assessment of their circulating leptin. 